\title{
Study of Strategies for Technological Factors to Be Involved in Income Distribution
}

\author{
Liqun $\mathrm{Li}^{1}$ \\ ${ }^{1}$ School of Economics, Northwest University for Nationalities, Lanzhou, China \\ Correspondence: Liqun Li, School of Economics, Northwest University for Nationalities, Lanzhou 730124, China.
}

Received: March 17, 2017

Accepted: April 30, 2017

Online Published: May 15, 2017

doi:10.5430/jms.v8n2p43

URL: https://doi.org/10.5430/jms.v8n2p43

This work was supported by the Fundamental Research Funds for the Central Universities of Northwest University for Nationalities (Grant No. 3192015115).

\begin{abstract}
With comprehensive development of the knowledge economy and the information economy, scientific and technological progresses have become the determinant factor of social and economic development. Many countries are making an all-out effort in developing technology industry and enterprises, fully arouse the enthusiasm and creativity of technology owners and make them the backbone force for the national economy and social development. Being the main driving force for the implementation of scientific and technological achievements, scientific and technological talents are very important links which shall never be overlooked. Only by rational and correct income distribution system as well as innovative and effective incentive model can the initiatives and creativity of scientific and technological talents be truly aroused. This article analyzed the necessity of technological factors being involved in income distribution and raised feasible suggestions regarding the implementation mechanism of the said involvement.
\end{abstract}

Keywords: technological factors, income distribution, strategy

\section{Introduction}

As knowledge economy and information economy fully develop, scientific and technological progresses have emerged as a determinant factor in social and economic development. Proportion of output value generated by scientific and technological progresses in GDP in developed countries has reached $60 \%$ to $80 \%$. According to statistics of the Organization for Economic Cooperation and Development (OECD), over 50\% of the GDP of its member states come from knowledge-based industries and enterprises, while the contribution of knowledge innovation in economic growth has increased sharply from 5\%-20\% in early 20th century to $80 \%-90 \%$ nowadays. To this end, many countries are making great efforts in developing their technological industries and enterprises and fully arouse the enthusiasm and creativity of technology owners and make them the backbone force for national economy and social development. At the same time, technological factors stand out of all other production factors as the core factor for a country or a region's competitiveness. Income distribution system is the driving mechanism of economic growth. Humans have been continuously changing the income distribution system, a constituent of the relations of production, to better suit the development of productivity.

The establishment of socialist market economy in China resulted in several types of distribution methods. It is the intrinsic requirement of the market economy to incorporate technological factors into income distribution according to their contributions and an objective requirement to promote technological innovations and realize effective allocation of resources. Ownership and contribution in the creation of use value shall not be deemed as the basis for technological factors to be involved in income distribution, involving technological factors in income distribution based on their contribution in the creation of value is consistent with Marx's Labor Theory of Value and thus has important theoretical and practical significances. 


\section{Necessity of Technological Factors' Involvement in Income Distribution}

\subsection{Intrinsic Requirement of the Socialist Market Economy System}

The Socialist Market Economy allows diverse forms of ownership to develop side by side, this determines that technological factors can take part in income distribution according to their contributions. As long as factors of production belong to different owners, people can use other people's factors of production without expense; if they wish to use other people's factors of production during production, they have to pay for it. The ownership of factors of production indicates the necessity of factors of production being involved in income distribution. While under the Socialist Market Economy System, diverse forms of ownership exist together and develop side by side. Therefore, factors of production such as technology, capital and labor etc. belong to different owners, even within the national economy, due to the organizational structure, enterprises, as independent legal persons and independent commodity producers, have to pay for the technological factors of each other they used during production.

\subsection{Objective Requirement to Promote Technological Innovations}

Science and technology are the primary productive forces. The establishment of incentive mechanism for technological innovations requires the combination of technological innovations and technological factors' contributions in the creation and wealth and value, the incomes of technological innovators shall be determined based on contributions of their technological factors. Only that provides continuous driving force to technological innovations. If the income distribution among people engaging in technological innovation is not based on technological factors, it will inevitably lead to equalitarianism in income distribution which in turn, lead to lack of driving force for technological innovation which severely impede technological advancements (Table 1). Under market economy conditions, the higher the contribution of one technology in the creation of wealth and value is, the more this technology is desired for social and economic development. And the higher the contribution of one technology in the creation of wealth and value is, the higher the income of the technology owner shall be.

Table 1. Types, Advantages, Advantages

\begin{tabular}{lll}
\hline Types & Advantages & Advantages \\
\hline Technology Awards & $\begin{array}{l}\text { Stimulate } \\
\text { employee } \\
\text { enthusiasm, }\end{array}$ & $\begin{array}{l}\text { Keep a relatively short period of time, Strong } \\
\text { Subjectivity }\end{array}$ \\
Science and technology project contracting & $\begin{array}{l}\text { Prevent } \\
\text { brain drain }\end{array}$ & No obvious incentive effect \\
Post skill salary & & Keep a relatively short period of time \\
Transfer of technological achievements & & Not easy to be supported \\
Profit sharing & & The operation of complex and difficult \\
Technology shares & & \\
\hline
\end{tabular}

\subsection{Objective Requirement to Realize Effective Allocation of Resources}

Involvement of technological factors in income distribution according to their contributions means that the producer pays owners of technological factors based on the contributions of these factors during production. That is to say, under the condition of pursuing maximum profit, producer determines the prices and demands for different factors of production by applying the profit maximization principle and equals marginal cost with marginal income to realize the optimization of different factors of production; while owners of factors of production acquire incomes via factors' market prices to realize local effective allocation of resources. Under the premise that the marginal costs of all products on the society equal to their marginal incomes, different factors of production have to have their proportions of income determined according to their contributions in production, thus, optimal resource allocation of the whole society can be realized.

\section{Study of Strategies for Technological Factors to Be Involved in Income Distribution}

\subsection{Summarize and Improve Operable Income Distribution Scheme in Practices}

Involving technological factors in income distribution is an exploratory task without much to refer to. But on the other hand, it is an orientated and systematic engineering, we encourage and support enterprises, higher education institution and research institutes to be bold in practice and summarize their experiences to guide the healthy 
development of this task. Due to the characteristics of technological factors, it is difficult to quantify their contributions in production, therefore, when formulating specific income distribution schemes, one shall fully consider the actual situations to design rational quantification approach, select income distribution mode which is suitable to the production manner, truly connect income of technological and managerial factors with their performances and contributions and fully reflect their involvement in income distribution. Choose different types of technological factors and conduct pilot tests, summarize the experiences and release a series of orientated policy suggestions, guide these practices in categories to enhance the pertinence of works.

\subsection{Enhance Intellectual Property Protection to Render a Legal Basis for Involvement of Technological Factors in Income Distribution}

Enhance intellectual property protection and improve the patent system. The reason for technological factors to be involved in income distribution is that they are, in fact, some property rights, i.e. they possess intellectual property rights. According to national laws which grant patents, patent owners enjoy exclusive rights on their patents within a defined period of time without other people being granted with the same patent. This exclusive property right must be effectively protected to guarantee the realization of related rights and interests. Therefore, policies, laws and regulations related to involvement of technological factors in income distribution shall be further amended and improved to enhance intellectual property protection and make involvement of technological factors in income distribution a legal requirement.

\subsection{Enhance the Intensity of Policy Advocacy and Expand Policy's Influence}

Currently, China's policies lay fairly low attention on the involvement of technological factors in income distribution and they usually focus on short-term income distribution behaviors only. Intensity of advocacy of policies and supervision of their implementations shall be greatly enhanced to create a atmosphere and common knowledge on the society that we value technological factors and wealth can be made by these technological factors. As for specific measures, advocate and interpret related policies with certain focuses to help enterprises and institutions to familiarize and understand the policies, and in turn effectively execute these policies to fully guarantee technological factors' involvement in income distribution.

\subsection{Improve the Corporate Legal Person Management System, Establish and Perfect Stock incentive System}

Corporate legal person management system directly hinders the effectively implementation of stock incentive system. Under the larger background of weakened function of stockholders' meeting, lack of owners of state-owned shares and severe problem of insider control, stock incentive might become the incentive of operators for themselves and turn stock incentive to a one-off welfare. In order to realize the incentivizing purpose of the stock incentive and realize enterprises' long-term benefits and strategic goals, corporate governance structures must be changed while internal supervision system must be enhanced. To this end, technological enterprises shall establish good relations among shareholders' meetings, board of directors and board of supervisors to form supervision and management of managers, enhance assessment, review and supervision of independent directors and board of supervisors on the stock incentive system, publish financial and operation status regularly and strictly control financial statements frauds.

\subsection{Matching Stock and Dividend Incentive Systems}

Enhance the coordination and linkage among policies related to stock and dividend incentive systems, study and resolve the prominent problems including "transfer of state-owned shares" and "double shoulder task" phenomenon of leaderships of higher education institutions and research institutes. For the issue of "transfer of state-owned shares", draw lessons from exemption regulations of state-owned venture capital enterprises and exempt the obligations for transfer of state-owned shares formed by technological investments of universities, research institutes and their independent technology transfer and transformation institutes as well as asses management companies. As for the issue of "double shoulder task", study the share-holding management methods of talents bearing "double shoulder tasks" among leaderships of higher education institutions and research institutes. Allow other talents who also bear "double shoulder tasks" outside the leaderships of higher education institutions and research institutes to enjoy benefits of policies related to transformation of scientific and technological achievements, allow investment of these achievements in lieu of shares, allow multiple jobs and multiple wages and improve matching supervision and management measures. Specify the methods of invest scientific and technological achievements in lieu of shares, improve laws and regulations regarding income gained from disposal of national assets, enhance connections of laws and regulations, policies and operations, eliminate some departments' concern about loss of state assets and corresponding responsibilities, boost the driving force of implementation of pilot units. 


\section{References}

Cai, J., \& Liu, L. (1999). Income Distribution of the Three Classes in China. China Youth Publishing House.

Chen, J. (1997). A Few Questions of Technology Investment. Enterprise Vitality, 11.

Ma, Y. (1992). Theory of Income Distribution. Shaanxi People's Publishing House.

Verna, A. (1998). The Knowledge Evolution (Chinese Translation Version). Zhuhai Publishing House.

Zhou, Z. (2002). Review of Practical Exploration and Improvement Measures of Involving Technological Factors in Income Distribution. Quarterly Magazine of Research Studies of Shanghai Academy of Social Sciences, 3. 